\title{
Comparison of Changes of Road Noise Level Over a Century Quarter: A Case Study of Acoustic Environment in the Mountainous City
}

\author{
Magdalena Daria Vaverková ${ }^{1,2}$, Eugeniusz Koda², Małgorzata Wdowska ${ }^{2, *}$ \\ 1 Department of Applied and Landscape Ecology, Faculty of AgriSciences, Mendel University in Brno, \\ Zemědělská 1, 61300 Brno, Czech Republic \\ 2 Institute of Civil Engineering, Warsaw University of Life Sciences - SGGW, Nowoursynowska 159, 02-776 \\ Warsaw, Poland \\ *Corresponding author's e-mail: malgorzata_wdowska@sggw.edu.pl
}

\begin{abstract}
An essential part of a sustainable city is sustainable transport; however, the development of transport has led to the growing noise pollution. It is obvious that the road-traffic noise has negative health impacts on the population in the cities. These effects should be reduced to ensure the sustainability of modern cities. The main purpose of the study was to compare the changes in the noise level in the mountainous city in 2012 and 2016 compared to 1990. A hypothesis was introduced that over the past 26 years, the level and severity of noise during the day and night increased along with traffic and the number of cars. In addition, a comparison of the value of the traffic intensity of passenger cars and trucks during the daytime in the years 2012-2016 was made. Additionally, the noise generated by vehicles during the day and night was compared. On the basis of the results obtained, it can be concluded that the level of noise during the daytime over the last 26 years has clearly decreased. The main factors that reduced the noise level were the improvement of the quality of vehicle fleet, directing transit traffic to the city beltways, as well as the local use of noise barriers. However, the level of noise intensity at night increased significantly. This is due to the increase in the total number of vehicles in the city and their high speed at this time.
\end{abstract}

Keywords: noise, traffic, vehicles, harmful emissions, health

\section{INTRODUCTION}

Noise is a typical example of harmful emissions to the environment related to the economic and civilization development. The road noise in cities is a global problem that has been widely studied in the past throughout the world (Lam et al., 2012; Fidler et al., 2015). The intensive development of the transport industry in recent decades has led to many environmental problems. One of them is the growing noise pollution resulting from the intense development of road traffic (Hamad et al., 2017; Di et al., 2018). What is more, in recent years, along with the development of industrialization and urbanization, the road noise pollution has increased significantly (Huang et al., 2015; Wen et al., 2019), especially in large cities. There are many studies on the noise pollution in road traffic of large cities conducted in the last thirty years demonstrating that traffic is the main source of noise in the urban environments (Phan Thi et al., 2010; Swain et al., 2012; Sánchez-Sánchez et al., 2015).

An essential part of a sustainable city is sustainable transport; however, the development of transport has led to the growing noise pollution. Urban noise is considered a serious factor affecting the public health (Basner et al., 2010; WHO, 2018; Monrad et al., 2016; Ongel et al., 2016; Seider et al., 2016; Roswall et al., 2018; Wen et al., 2019). Regular and prolonged exposure of people to increased noise can cause adverse health consequences, such as: hearing impairment, hypertension, heart disease, irritability or sleep disturbances (Hume et al., 2012; Li et al., 2016; Kreuzberger et al., 2019). Enoksson Wallas 
et al., (2020) report that noise can act as a stressor and lead to a release of stress hormones and/ or an imbalance in the stress-regulating mechanism. Moreover, there is emerging evidence for an association between the environmental noise exposure and cardiovascular as well as metabolic diseases in adults (WHO, 2019). Therefore, these effects should be reduced to ensure the sustainability of modern cities.

On the basis of research, the maximum safe noise level without harmful effects on the human health was found to be $70 \mathrm{~dB}$ (A) at 24-hour exposure (European Environment Agency, 2019). The noise levels of $85 \mathrm{~dB}(\mathrm{~A})$ or more can cause permanent hearing damage or even hearing loss ( $\mathrm{Li}$ et al., 2016; Kreuzberger et al., 2019). In the European Union (EU), exposure to excessive noise $(>55 \mathrm{~dB})$ is recognized as a serious problem that worsens the health of the population (Figure 1).

Table 1 shows the exposure to road noise in Europe in 2016 (for comparison, the analyzed city was also included in the table). Road noise clearly contributes to the greatest level of exposure within the European population. It applies to at least 125 million people exposed to the noise levels above the threshold given in the Environmental Noise Directive (END) of $55 \mathrm{~dB}$ at night (European Environment Agency, 2019).

In western Europe only, every year one million people die due to the diseases and complications associated with excessive noise (Andersson et al., 2020). The number of people exposed to noise pollution in the urban areas continues to increase due to the expansion of transport, residential areas, and infrastructure. With continuing urbanization and population growth, traffic noise is a growing problem. (Paull et al., 2020). In fact, the noise generated by the transport infrastructure is the main source of noise pollution in the urban areas (Bouzid et al., 2020). Measurements of the road noise intensity in the urban areas are essential for proper environmental management. They can also be the primary source of the data used for proper road noise management, and especially when developing the local land use plans that take into account constructing noise-sensitive buildings (e.g. housing estates, hospitals, recreation centers, schools) away from the most burdensome sources of noise (roads with heavy traffic). The noise distribution maps can also be used to protect sensitive buildings, e.g. by using acoustic screens, additional security in the structure (e.g. walls) and building construction (e.g. windows).

Noise levels are usually expressed by specific types of noise indicators. There are several types of indicators, e.g. noise indicator (Sehut, 1972), noise impact indicator (Nassiri et al., 2016) or noise pollution indicator (Jeon et al., 2018), which were developed to measure the intensity and assess the impact of noise on the surroundings.

In order to assess road noise in cities, two strategies are usually used. In the first, the noise level is measured directly on the streets in situ, and in the second, the noise is estimated using numerical modeling performed by means of appropriate software. Both methods are included in the END (Paull et al., 2020). Although the numerical modeling methods have high potential and are usually proposed for noise mapping, they must be supplemented and verified by the in situ measurements (Manwell et al., 2011).

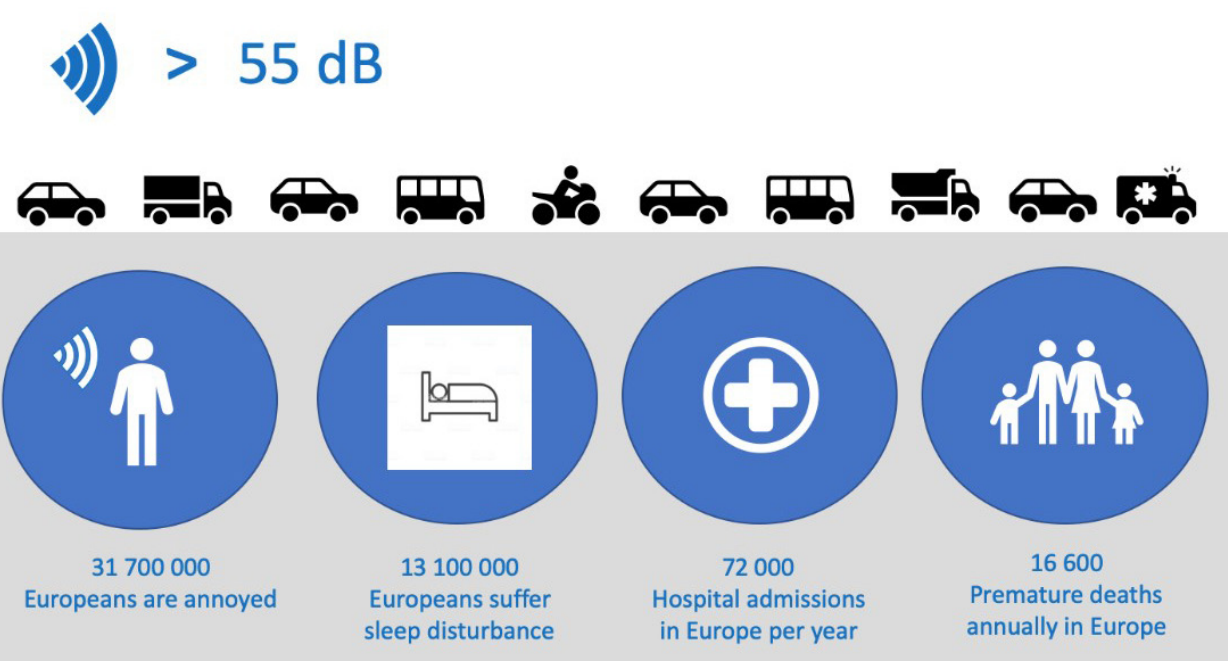

Figure 1. Impact of noise in Europe (edited by authors) (European Environment Agency, 2019) 
Table 1. Capital cities in Europe: percentage of people exposed to night dB values due to the road noise exposure (European Environment Agency, 2016 edited by authors)

\begin{tabular}{|c|c|c|c|c|}
\hline $\begin{array}{c}\text { Capital cities } \\
\text { in Europe }\end{array}$ & $\begin{array}{c}\text { Night } \\
50-55 \mathrm{~dB} \\
(\% \text { of people) }\end{array}$ & $\begin{array}{c}\text { Night } \\
\text { more than 55 dB } \\
\text { (\% of people) }\end{array}$ & $\begin{array}{c}\text { Area } \\
\left(\mathrm{km}^{2}\right)\end{array}$ & $\begin{array}{c}\text { Population } \\
\text { (worlddata.info) }\end{array}$ \\
\hline Sofia & 31.88 & 39.06 & 1.310 & 1.238 .438 \\
\hline Luxemburg & 35.60 & 32.79 & 151 & 116.323 \\
\hline Tallinn & 25.03 & 25.85 & 415 & 1.897 .491 \\
\hline Vienna & 20.15 & 22.01 & 454 & 658.390 \\
\hline Oslo & 17.74 & 22.23 & 88 & 616.098 \\
\hline Copenhagen & 19.29 & 19.69 & 115 & 553.165 \\
\hline Dublin & 14.37 & 22.16 & 518 & 1.764 .615 \\
\hline Warsaw & 14.89 & 18.04 & 185 & 639.227 \\
\hline Helsinki & 18.54 & 13.90 & 52 & 133.883 \\
\hline Bern & 15.11 & 17.16 & 1.572 & 8.673 .713 \\
\hline London & 11.50 & 18.30 & 402 & 546.382 \\
\hline Vilnius & 16.44 & 12.20 & 130 & 864.217 \\
\hline Amsterdam & 13.55 & 11.85 & 275 & 124.644 \\
\hline Reykjavik & 8.44 & 10.73 & 0.55 & 5.735 \\
\hline Valletta & 5.33 & 9.85 & 892 & 3.644 .826 \\
\hline Berlin & 5.05 & 8.89 & 124.51 & 174.370 \\
\hline Bielsko-Biała & 12.0 & 14.5 & & \\
\hline
\end{tabular}

There are many models for forecasting road noise in the world, but these models cannot be directly generalized because the local location and environmental conditions generally affect noise levels (e.g. vehicle type and weather, terrain, type of building) and are also different for various locations (Halim et al., 2017). That is why in situ testing is so important. Modeling should also take into account the planned economic development in the analyzed area (city), for which the measurements carried out in earlier periods are very useful. They result in the trends of developmental changes and the associated emission levels (observational method). This type of analysis was carried out as a part of this work.

The main purpose of the study was to compare the change in the increase/decrease in the noise level in 2016 compared to 1990 in a mountainous city located in the south of Poland. The specific purpose of the work was to compare the change in noise level at night and during the day at selected points in the city. A hypothesis was introduced that in the selected city, the level and severity of noise during the day and night increased over the past 26 years along with traffic and the number of cars. In addition, a comparison of the value of the traffic intensity of passenger cars and trucks (vehicle/day) during the daytime in the years 2012-2016 was made. A comparison of the noise generated by vehicles during the day and night was also performed.

\section{MATERIALS AND METHODS}

The object of research was the city of BielskoBiała located in the southern part of the Silesian Voivodship $\left(49^{\circ} 49^{\prime} 21^{\prime \prime} \mathrm{N} 19^{\circ} 02^{\prime} 40^{\prime \prime} \mathrm{E}\right)$. The greater part of the city lies in the Silesian Foothills, which is part of the macro-region of the Western Beskids Foothills (Figure 2). The area of the city is about $124.51 \mathrm{~km}^{2}$, including: residential areas: $16.4 \%$, service areas: $2.6 \%$, industrial and storage areas: $3.6 \%$, communication areas: $11 \%$, agricultural areas: $14.6 \%$, forest areas: $24.2 \%$, urban greenery: $2.2 \%$, and other areas: $25.4 \%$. The city is a tourist attraction of the region. It lies on the access route to border crossings in Cieszyn and Zwardoń. Several roads of national importance converge at the Bielsko road junction, i.e. 1 (S1), 52, (S52), 940, 942 and 944.

The city area is located within two climatic districts: Subcarpathian (foothills) and Carpathian (mountains), which causes irregular weather conditions, including high temperature fluctuations in the annual cycle. During the year, the west and southwest winds prevail. The southwest and south winds are more frequent in winter, while in the summer - the west and north-west winds. The highest cloudiness occurs from November to January, and the highest number of sunny days occurs between the end of summer and the beginning of autumn. 


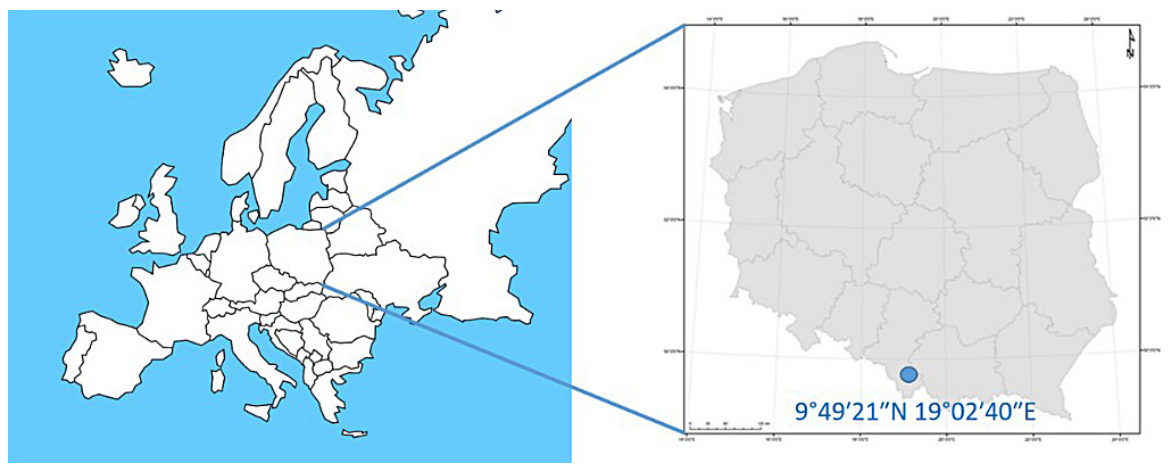

Figure 2. Study site location

The structure of the industry in Bielsko-Biała has undergone a significant transformation in the last 20 years. This change was mainly related to the collapse of the textile industry, which was so far leading in the city. As a result of the economic and political transformation processes, many plants were closed, some were privatized, and production and employment in the industrial sector were significantly reduced. The light industry, dominating for over two centuries, gave way to the electro-rail industry, especially the automotive industry (Haczek, 2014).

The location of measuring points was adopted at the main arterial roads of the city, taking into account the proximity of the road in terms of distance from residential buildings, as well as the rate of occurrence in the stream of moving means of transport (vehicles) on the city's arterial roads. In total, 19 measurement points were selected in the city (Figure 3), including: (i) the exact center (4 measurement points), (ii) the areas adjacent to the center located near 940 driveway (ul. Lwowska, 9 measurement points), and (iii) the north-western part of the city located away from the city center driveways (6 measurement points). The 1990 raw dataset come from the Provincial Environmental Protection Inspectorate and measurements carried out in 2012 and 2016 are part of the Program of Environmental Protection Against Noise in the city.

The noise measurements on selected communication routes of the city were carried out in accordance with the recommendations of the Polish Regulation of the Minister of the Environment (2011). The regulation defines the methodology for measuring noise in the environment in connection with the operation of land, water and air means of transport. In accordance with the European and Polish legislation, the noise level analyzer was mounted at a distance of $10.0 \mathrm{~m}$ from the noise source, at a height of $4.0 \mathrm{~m}$ above ground level. The noise measurements were conducted in limits: temperature $-10^{\circ} \mathrm{C}$ to $25^{\circ} \mathrm{C}$, humidity from $25 \%$ to $98 \%$, wind speed up to $5 \mathrm{~m} / \mathrm{s}$ and atmospheric pressure from 900 to $1100 \mathrm{hPa}$. The level of road noise was measured at all the points during every count in September, October and November. The traffic noise was measured on weekdays in comparable and stable weather (no rain or high winds). In order to supplement the analyses, a comparison of the value of passenger and truck traffic (vehicle/hour) was made during the daytime in the years 2012-2016. A comparison was also made of the noise generated by vehicles during the day and night. In total, 34 measuring points were compared throughout the city.

\section{RESULTS}

Road noise is one of the most disruptive types of noise in the city (Ko et al., 2011; Mehdi et al., 2011; Park et al., 2018), which significantly influences the formation of the acoustic climate of the environment. The noise emissions from road traffic depend on several factors, such as traffic, heavy vehicles vehicle speed road surface type and road gradient (Suárez and Barros, 2014). The road noise resulting from vehicle traffic includes noise generated at the tire-surface contact point (Cabral et al., 2015; Li et al., 2016) and noise from fuel combustion (i.e. engine operation propulsion system exhaust system) (Park et al., 2018). The coexistence of many other factors that make up the noise source and their variability significantly complicate a full road noise assessment. The applicable and used road noise assessment indicators (measures) take into account the physical sound parameters in the relation: source - propagation path - receiver. Figure 4 presents a comparison of 

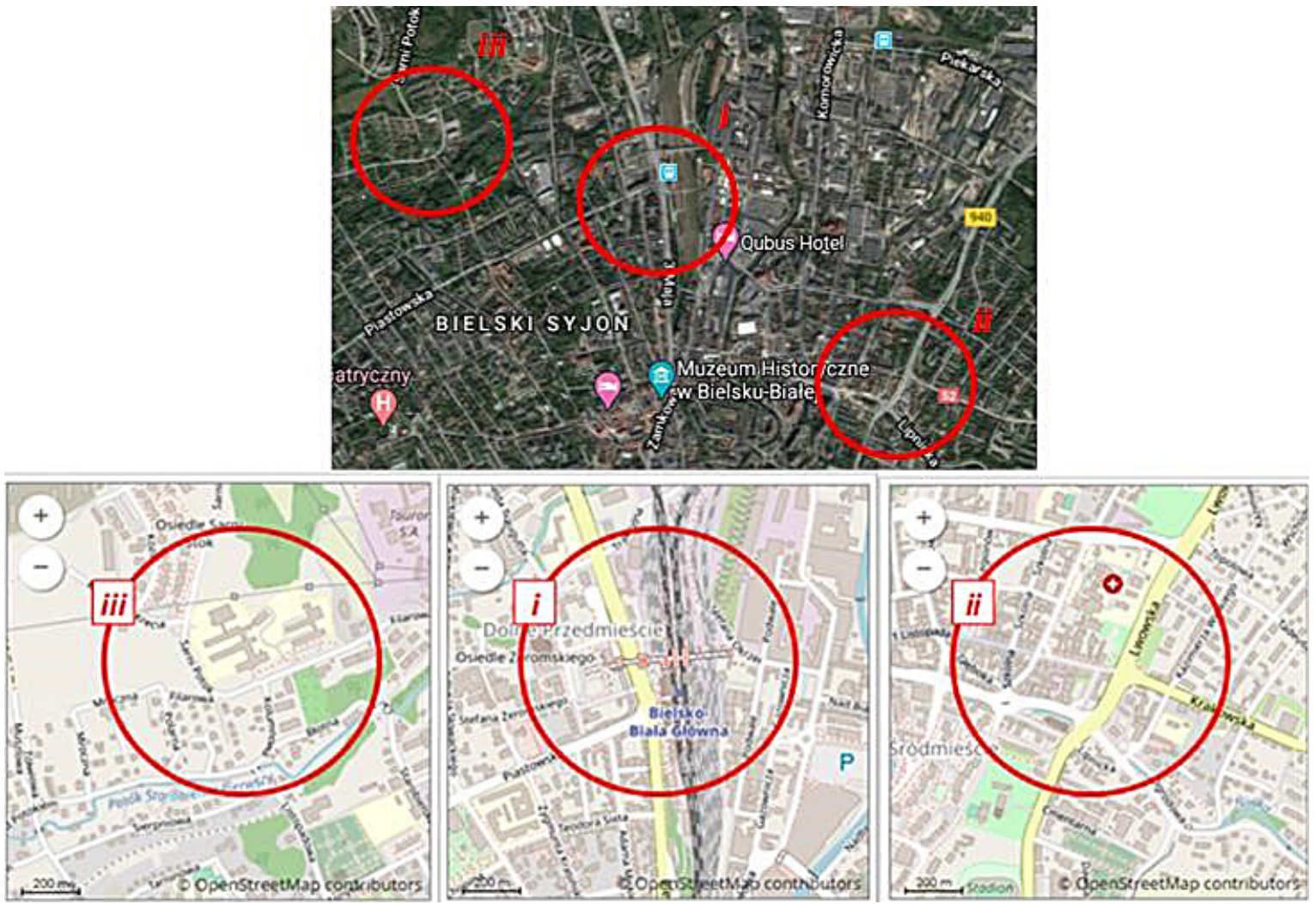

Figure 3. Location of noise level measuring points (Google maps, 2019; Traseo, 2019) (edited by authors)

the intensity of road noise during the daytime in the city in 1990 and 2016.

According to the analysis the level of noise during the daytime at all compared measuring points of the city over the years 1990 and 2016 has significantly decreased. At the intersection of ul. Piastowska and ul. Warszawska (around the railway station: $\left.49^{\circ} 49^{\prime} 46.0^{\prime \prime} \mathrm{N} 19^{\circ} 02^{\prime} 38.6^{\prime \prime} \mathrm{E}\right)$ by $10.2 \mathrm{~dB}$, and on ul. Poligonowa $\left(49^{\circ} 50^{\prime} 53.2^{\prime \prime} \mathrm{N}\right.$ $\left.19^{\circ} 01^{\prime} 10.4^{\prime \prime} \mathrm{E}\right)$ that is parallel to ul. Bohaterów Monte Casino (49 $\left.50^{\prime} 54.0^{\prime \prime} \mathrm{N} 19^{\circ} 01^{\prime} 41.3^{\prime \prime} \mathrm{E}\right)$, the noise level was lower by as much as $12.1 \mathrm{~dB}$. This is the result of a change in the quality of vehicle fleet replacement of old articulated IKARUS buses with "quiet" modern low-floor buses, as well as diversion of some transit traffic to the newly built city beltways. In the second case, the decrease in the noise level was caused by the construction of noise barriers along ul. Bohaterów Monte Casino $\left(49^{\circ} 50^{\prime} 54.0^{\prime \prime} \mathrm{N} 19^{\circ} 01^{\prime} 41.3^{\prime \prime} \mathrm{E}\right)$ in the period between the analyzed years. It should be noted that the decrease in noise intensity occurred despite the

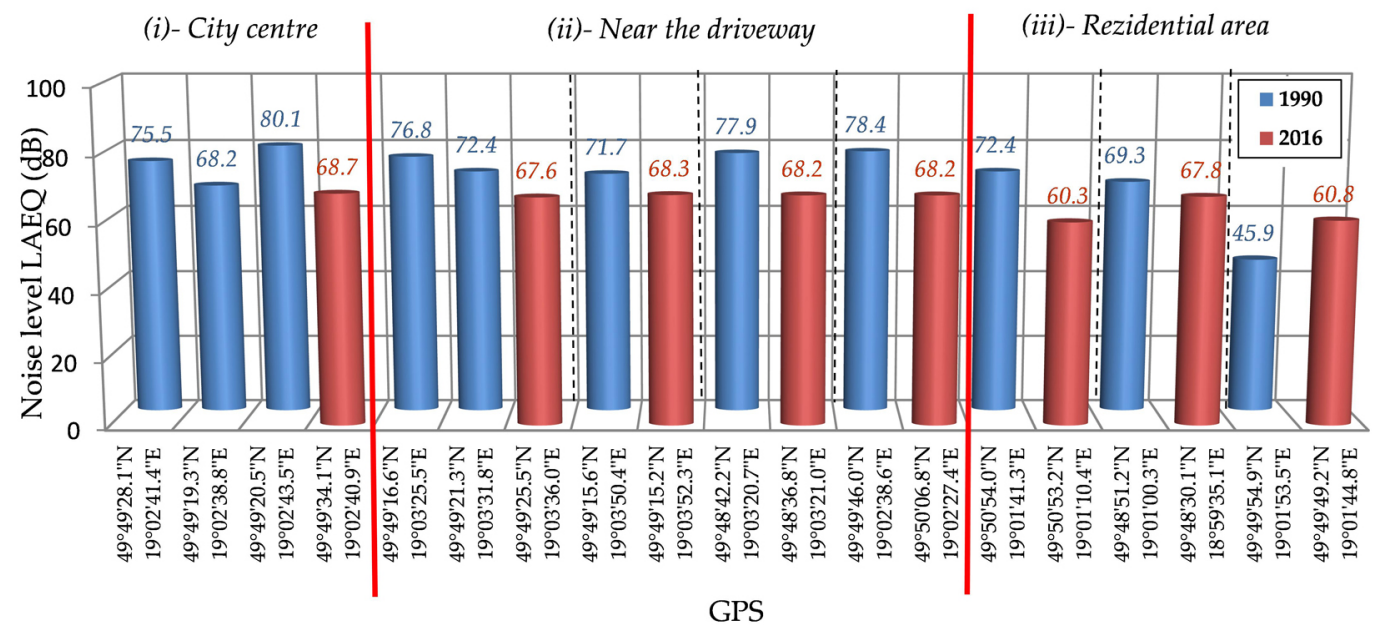

Figure 4. Intensity of road noise during the daytime in the years 1990 and 2016 
increase in vehicle traffic. The average decrease in the noise level in the city center decreased by $4.9 \mathrm{~dB}$. Only in one case, the road noise level increased significantly by as much as $14.9 \mathrm{~dB}$. This applies to ul. Nad Potokiem (49 $49^{\prime} 54.9^{\prime \prime} \mathrm{N}$ $\left.19^{\circ} 01^{\prime} 53.5^{\prime \prime} \mathrm{E}\right)$. Such an increase is related to the expansion of the "Sarni Stok" housing estate and the opening of an access road to the "Sarni Stok" shopping center. The once "not busy" area in the 1990s has now become an area of "high traffic". Figure 5 presents a comparison of the road noise levels at night in the city in 1990 and 2016.

It can be stated that the noise level at night at all comparable measuring points of the city in 2016 increased significantly when compared to 1990 . The comparison clearly shows that the growth in the number of vehicles has increased the noise level. At the intersection of ul. Piastowska and ul. Warszawska (around the railway station: $\left.49^{\circ} 49^{\prime} 46.0^{\prime \prime} \mathrm{N} 19^{\circ} 02^{\prime} 38.6^{\prime \prime} \mathrm{E}\right)$ the noise level at night increased by $6.5 \mathrm{~dB}$, and the average road noise level in the city center at night increased by over $10 \mathrm{~dB}$. This is the result of a significant increase in the vehicle traffic resulting from an increase in the total number of vehicles in the city and a greater (too high) speed of movement at this time of day. In the case of ul. Nad Potokiem (49 49'54.9'N 1901'53.5'E), the road noise level increased from a very low level of $23.7 \mathrm{~dB}$ to a level of $50.4 \mathrm{~dB}$, i.e. by $26.7 \mathrm{~dB}$ (although as to the absolute value it is still not too high). This is due to the same reasons as the daytime noise level increase. Figure 6 presents the intensity of the road noise level at daytime and night in the years 1990 and 2016.

Mean noise level values collected from measurement point (i), (ii), (iii) are presented in
Figure 7a- daytime and 7b- nighttime. The data presented in Figure 7a clearly indicates that the mean value of noise level in city center (i) and close vicinity (ii) during daytime, is lower in 2016 than it was in 1990. This significantly improves the acoustic comfort and decrease the noise nuisance in the city. The analyses of the transport generated noise revealed, that the citizen's health can be affected by high acoustic levels (exceeding $70 \mathrm{~dB}$ ) (Zielone wrota, 2019). Decreasing the mean transportation noise level down to $<70 \mathrm{~dB}$, allows declassifying according the standard acoustic scale from category "very high nuisance" to "high nuisance", which is a preferable trend. However, it needs to be borne in mind that even though the level of noise has decreased, it is still too high. The national and international studies indicate a general trend of an increase of citizen's negative assessment of the noise level exceeding in daytime LAeq $=55 \mathrm{~dB}$ (Kaddoura et al., 2017). The data presented in Figure $4 \mathrm{~b}$ shows that the mean noise level during nighttime increase in every measurement point. This significantly affects the acoustic comfort and increases the noise threat. When the night noise level exceeds $50 \mathrm{~dB}$, then nearly $50 \%$ of citizens involved in the study, were complaining on experiencing the sleeping discomfort, cardiac neurosis was observed in $40 \%$, and over $15 \%$ of the studied citizens were diagnosed with exhaustion and tiredness.

The traffic intensity of passenger cars and trucks (vehicle/hour) in the daytime and the intensity of their noise during the day and at night in the analyzed city for 2012 are presented in Figure 8 in which: Q1 means the traffic intensity (vehicle/hour) of passenger cars, Q2 - the traffic

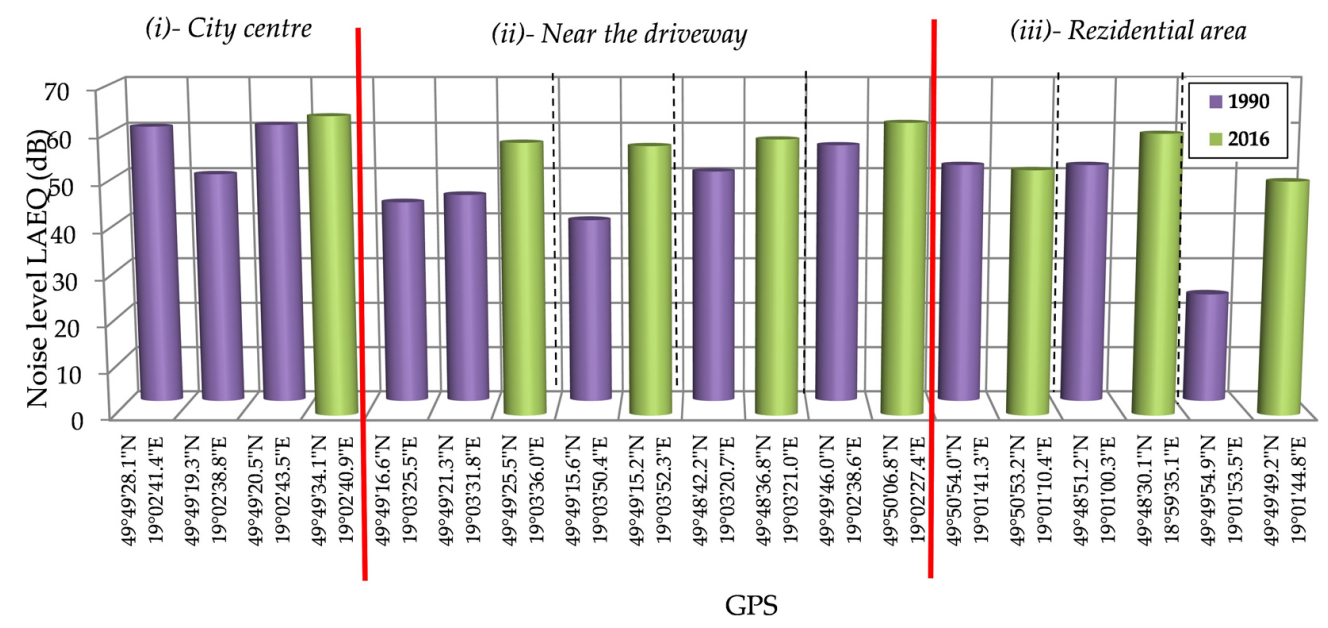

Figure 5. Intensity of road noise level at night in the years 1990 and 2016 


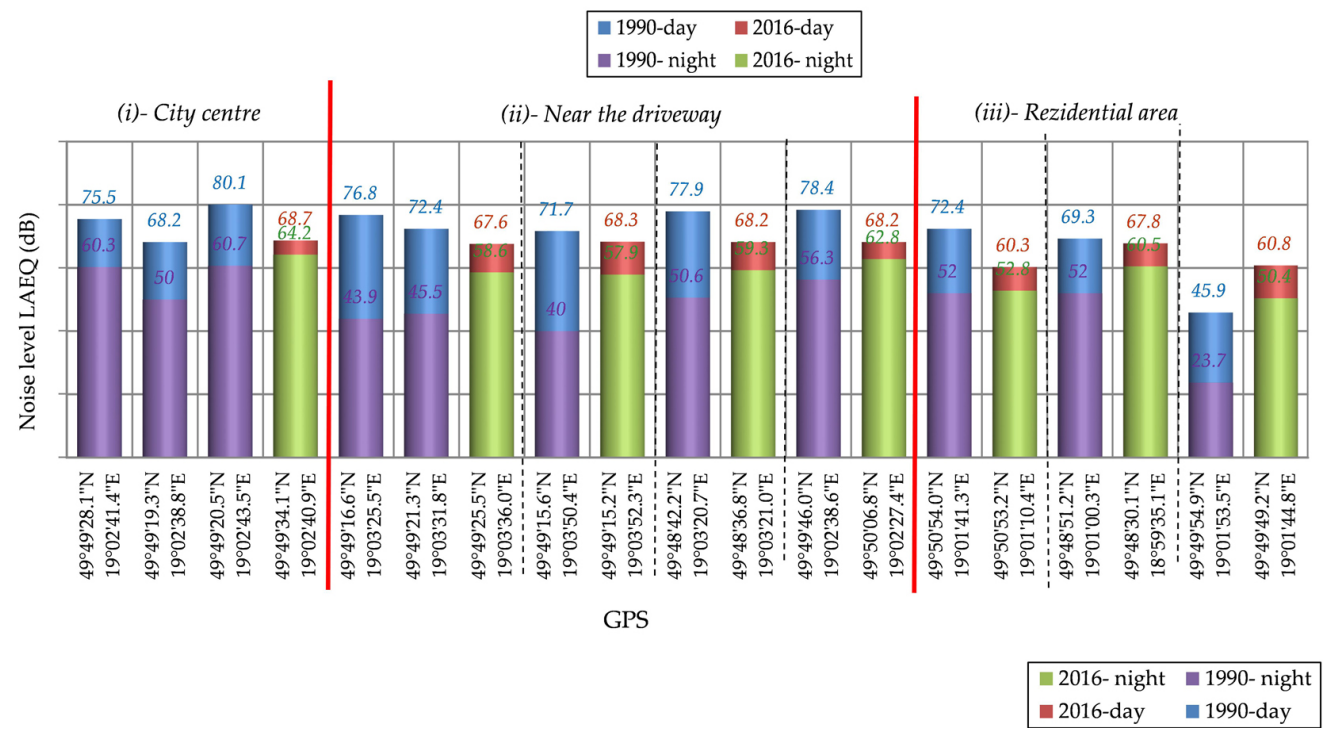

Figure 6. Intensity of the road noise level at daytime and night in the years 1990 and 2016
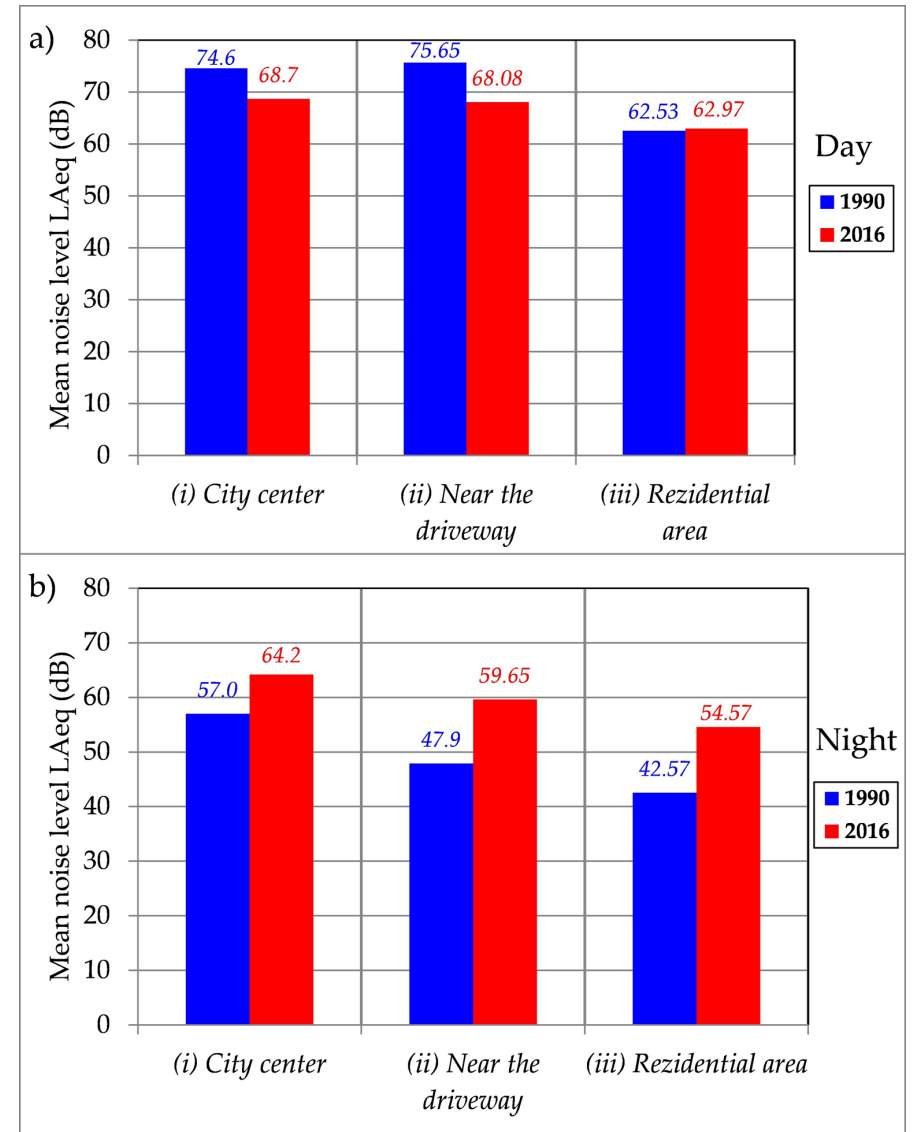

Figure 7. Mean values of the road traffic noise levels during daytime (a) and nighttime (b) in 1990 and 2016

intensity (vehicle/hour) of trucks, Q - the total traffic volume, LD - the noise level during the daytime in $\mathrm{dB}$ and $\mathrm{LN}$ - the noise level during the night in $\mathrm{dB}$.

The traffic intensity of passenger cars and trucks (vehicle/hour) in the daytime and the intensity of their noise during the day and at night in the analyzed city for 2016 are presented in Figure 9 (Appendix 4), in which: Q1 means the traffic intensity (vehicle/hour) of passenger cars, Q2 - the traffic intensity (vehicle/hour) of trucks, $\mathrm{Q}$ - the total traffic volume, LD - the noise level 


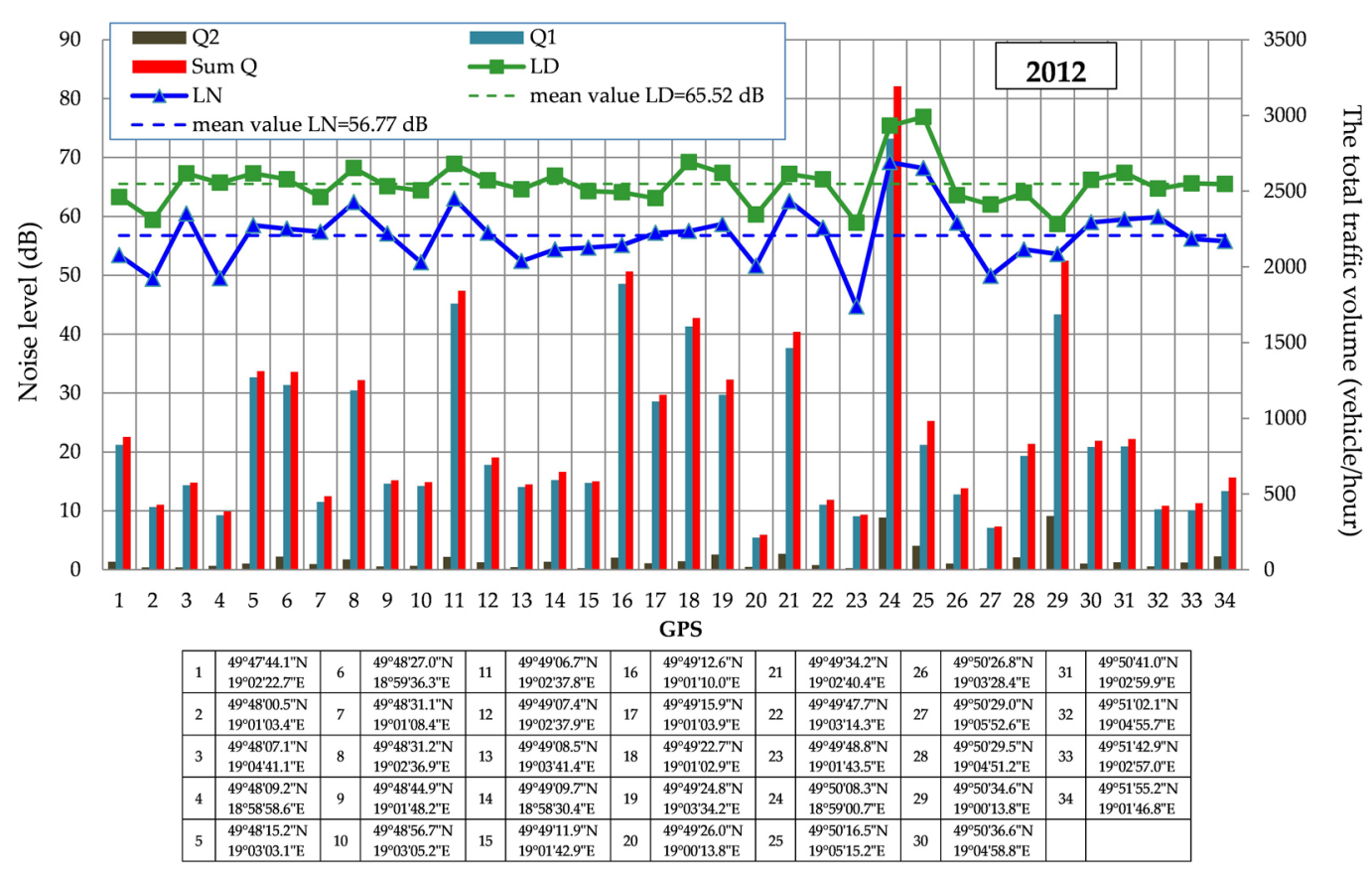

Figure 8. Traffic intensity of passenger cars and trucks (vehicle/ hour) and the volume of noise generated by them in 2012

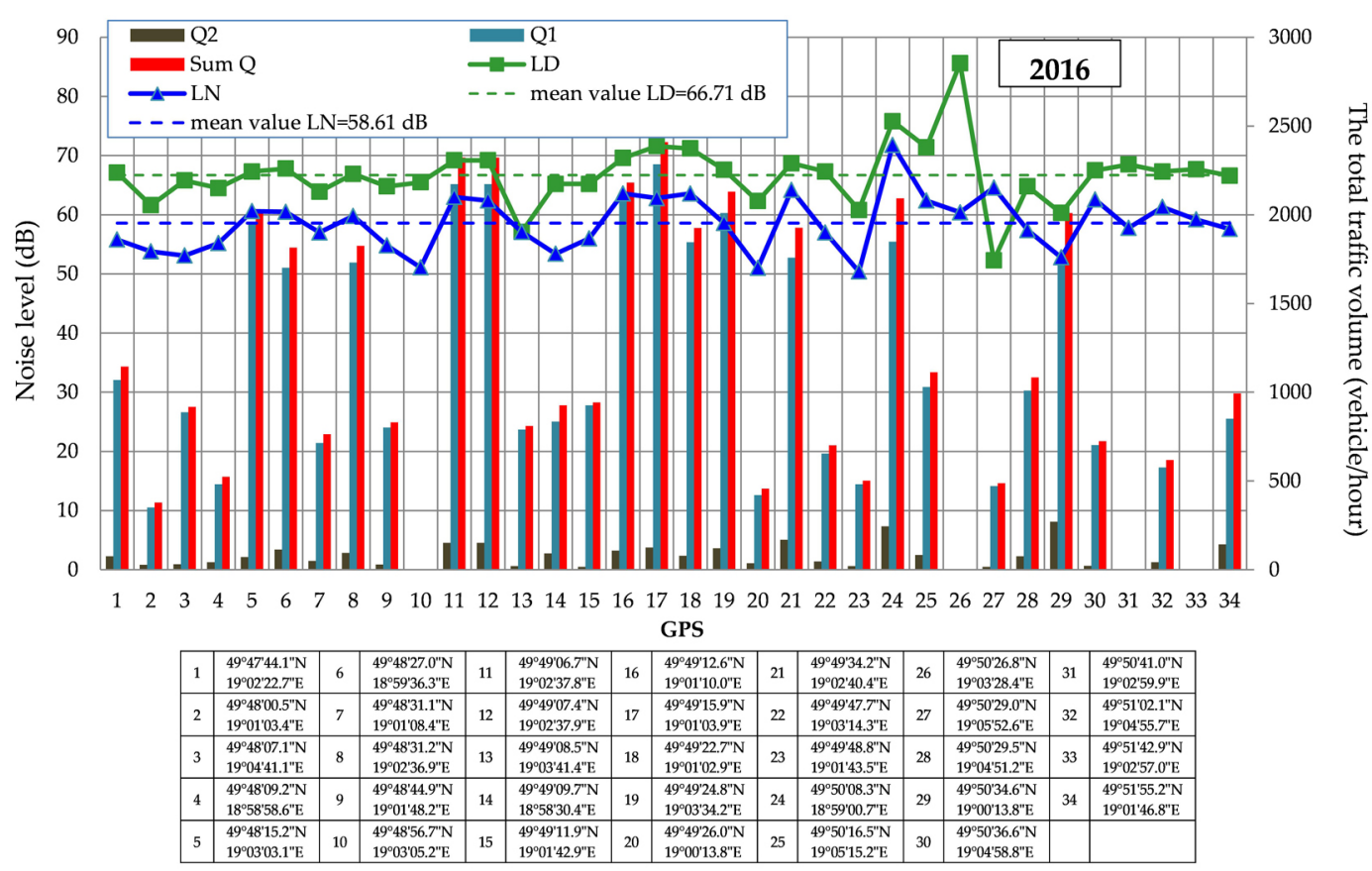

Figure 9. Traffic intensity of passenger cars and trucks (vehicle/ hour) and the volume of noise generated by them in 2016

during the daytime in $\mathrm{dB}$ and $\mathrm{LN}$ - the noise level during the night in $\mathrm{dB}$.

Figure 10 presents the noise level changes depending on car traffic intensity in 2012 and 2016. Figure 10a presents the changes of noise level in 2012 and 2016 depending on the number of vehicles per hour, for day and nighttime. The vehicle traffic intensity significantly increases, which caused the increase the noise level both and day and nighttime. What should rise particular awareness in terms of acoustic comfort of the citizens is a significant increase of the nighttime noise level (Figure 10b), which indicates intensification of car traffic during nights. 

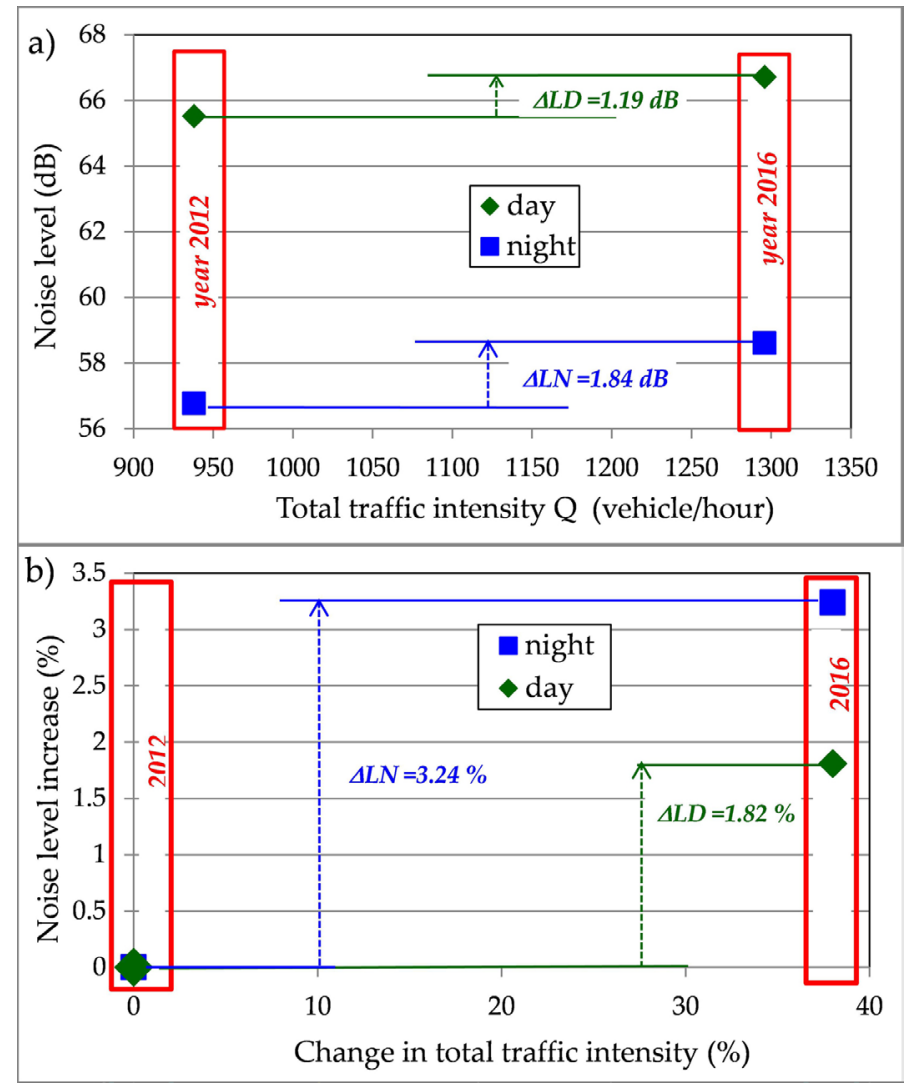

Figure 10. The road noise level depending on the traffic intensity (a) and change in total traffic (b) intensity for day and nighttime

\section{DISCUSSION}

While analyzing the changes in the intensity of passenger and truck traffic (vehicle/hour) in the daytime and the volume of noise they generate during the day and at night in the city in 2016 compared to 2012, it can be stated that there was an average increase in traffic $(\Delta \mathrm{Q} 1)$ of passenger cars from 871 to 1211 (vehicles/hour), i.e. by $39.06 \%$. The traffic intensity $(\Delta \mathrm{Q} 2)$ of trucks increased from 67 to 85 (vehicles/hour) i.e. by $27.29 \%$. Total traffic $(\Delta Q)$ increased from 938 to 1296 (vehicles/ hour) i.e. by $38.22 \%$. The changes in the noise levels can also be seen by comparing the time of day. The daytime noise levels $(\Delta \mathrm{LD})$ increased from $65.52 \mathrm{~dB}$ to $66.71 \mathrm{~dB}$, i.e. by $1.81 \%$ while at night $(\Delta \mathrm{LN})$ increased from $56.77 \mathrm{~dB}$ to $58.64 \mathrm{~dB}$, i.e. by $3.2 \%$. Decrease of the daytime noise level over last 26 years is most probably an effect of transport infrastructure improvement and technological development in the vehicle production standards. However, the increase of the noise level in nighttime could be caused by intensification of transit, logistics and shipment development, and also change of the night life citizens' habits.
In 2018, WHO published the recommendation and guidelines on noise control and health protection for communities. According to the regulation, the level of noise outside the building should not exceed $55 \mathrm{~dB}$ during daytime and $45 \mathrm{~dB}$ during nighttime (WHO, 2018). Maintaining such level of noise allows appropriate acoustic conditions in the spaces with occasionally opened windows.

In Germany, the limit values for daytime traffic noise levels vary depending on the type of land and building use, e.g. $57 \mathrm{~dB}$ (A) for hospitals schools sanatoriums and retirement homes, $59 \mathrm{~dB}$ (A) for residential areas, $69 \mathrm{~dB}$ (A) for commercial areas (Kaddoura et al., 2017). The nighttime limits are reduced by $10 \mathrm{~dB}(\mathrm{~A})$ compared to the time of day. Comparing these data with the data for the city it can be seen that the mountainous city does not meet the acoustic requirements compared to other EU countries, e.g. Germany. For noise at night, WHO Europe (2009) recommends a significantly lower noise level of $40 \mathrm{~dB}$ (A) (Kaddoura et al., 2017). Therefore, the noise intensity at night in the city under analysis is significantly exceeded in relation to these standards. 
The environmental pollution related to transport has many aspects, but two of them are particularly bothersome: emission of harmful exhaust gases and vibroacoustic effects, with particular significance of noise impact (Jacyna et al., 2017; Tang et al., 2018). The analysis of the available data on noise exposure in the city shows consistently that the dominant source of noise in this city as in other EU countries is road traffic (Jarosińska et al., 2018). The situation is similar in many EU cities as well as in the world. For example, the studies conducted in the Portuguese city of Viana do Castelo confirmed that the most important source of noise and at the same time air pollution is the main road-avenue (Avenida 25 de Abril) which crosses the city dividing it into two parts (Silva et al., 2012). Ross et al., (2011) investigated the overall noise level in New York City which showed high variability on weekends as well as during day and night. All noise rates were moderately higher on weekdays compared to the weekend days. The authors also noted that on weekdays, the overall noise increased sharply in the early morning (4 am) and decreased sharply after $9 \mathrm{pm}$. On morning weekends, the noise increase started a little later (from 5 am to $6 \mathrm{am}$ ) and the nighttime decrease was more gradual (Ross et al., 2011). The studies in Hong Kong (Lam et al., 1998) have shown that $36.2 \%$ of the population suffers from the street noise that exceeds the government guidelines. It was confirmed that the average daily noise values ranged from 54.4 to 70.8 dBA while the average night levels ranged from 52.6 to $67.9 \mathrm{dBA}$ (To et al., 2015). In the case of the mountainous city in question, the average daily noise levels ranged from 53.3 to $73.1 \mathrm{dBA}$ depending on the measurement site, while the average night levels ranged from 37.0 to $59.5 \mathrm{dBA}$. It is also important to note the large differences in noise exposure not only between cities, but also within cities themselves. For example, the noise in Seoul (Korea) for night hours is $55 \mathrm{dBA}$ and varies between 15 and $65 \%$ between the city's districts (Lee et al., 2014). A similar situation can be observed in the examined city. In many countries around the world, noise has been recognized as a significant form of environmental pollution. Governments are interested in it, especially in highly industrialized countries (e.g. USA, Canada, Japan and many European countries) (Lee et al., 2014).

\section{CONCLUSIONS}

Nowadays, the noise generated by means of transport in most cities exceeds the acceptable levels. In many cities, due to the lack of beltways, built-up areas run through major communication routes including local and transit traffic. This results in high traffic and a significant level of noise propagated to the urban environment and affecting the overall acoustic climate. In recent years, there has been a rapid development of the infrastructure of the analyzed city. The number of inhabitants has not increased, in contrast to the number of cars and vehicle traffic (a significant increase in the number of cars per 1000 inhabitants). The number of roads for urban transport has also increased. The main purpose of the analysis was to compare the change in the noise levels in 2016 compared to 1990 in a mountainous city located in southern Poland. On the basis of the analysis of the measurement results obtained, it can be concluded that the level of noise during the daytime at all compared measuring points of the city over the last 26 years has clearly decreased. The main factors that reduced the noise level were the improvement of the quality of vehicle fleet, directing transit traffic to the city beltways, as well as the local use of noise barriers. However, the level of noise intensity at night at all compared measuring points of the city increased significantly. This is due to the increase in the total number of vehicles in the city and their high (too high) speed at this time. This condition is also influenced by the lifestyle of inhabitants in the cities with developed tourism. Moreover, at night, the impact of noise from the roads may be more influenced by transit and freight traffic, and by climatic factors. Further research is needed. When it comes to comparing the years 2012 and 2016 in terms of preventive measures, it can be said that the exit streets from the city were modernized. The elements slowing down traffic on the roads, like islets at pedestrian crossings, and speed limits of $30-40 \mathrm{~km} / \mathrm{h}$ on housing estates and singlefamily housing districts were introduced, which had a positive impact on the improvement of the acoustic climate of the analyzed city. However, this study demonstrated that the government of the city urgently needs to take actions to reduce the noise intensity at night. There is also a need to enforce a road noise reduction policy to make the nighttime climate more tranquil at a city level. 


\section{Acknowledgments}

We would like to express great appreciation towards Mgr. Ing. Staszek Sikorski for valuable consulting for this work and his assistance and willingness to provide his time so generously.

\section{REFERENCES}

1. Andersson E.M., Ögren M., Molnár P., Segersson D., Rosengrend A., Stockfelt L. 2020. Road traffic noise, air pollution and cardiovascular events in a Swedish cohort. Environmental Research, 185, 109446.

2. Basner M., Müller U., Griefahn B. 2010. Practical guidance for risk assessment of traffic noise effects on sleep. Applied Acoustics, 71(6), 518-522.

3. Bouzid I., Derbel A., Elleuch B. 2020. Factors responsible for road traffic noise annoyance in the city of Sfax, Tunisia. Applied Acoustics, 168, 107412.

4. Cabral M.F.F., Albuquerque F.S., de Freitas Neto O., Albuquerque T.M.A. 2015. Study of Mechanisms That Generate Traffic Noise in the Tire-Pavement Interface for Low-Volume Roads in Brazil. Transportation Research Record, 98-107.

5. Di H., Liu X., Zhang J., Tong Y., Ji M., Li F., Feng T., Ma Q. 2018. Estimation of the quality of an urban acoustic environment based on traffic noise evaluation models. Applied Acoustics, 141, 115-124.

6. Enoksson Wallas A., Eriksson C., Ögren M., Pyko A., Sjöström M., Melén E., Pershagen G., Gruziev A. 2020. Noise exposure and childhood asthma up to adolescence. Environmental Research, 185, 109404.

7. European Environment Agency. Available online: https://www.eea.europa.eu/soer-2015/europe/ noise\#tab-related-briefings (accessed on 20 December 2019).

8. Fiedler P.E.K., Zannin P.H.T. 2015. Evaluation of noise pollution in urban traffic hubs-Noise maps and measurements. Environmental Impact Assessment Review, 51, 1-9.

9. Google maps. Available online: ttps:// www.google.com/maps/place/BielskoBiala/@49.812179,18.9672225,12z/data=!3m1!4 b1!4m5!3m4!1s0x47169f63dd80507b:0x6811f58 7fa4fe3a7!8m2!3d49.8223768!4d19.0583845 (accessed on 20 December 2019).

10. Haczek A. 2014. Transformation of industrial structures in Bielsko-Biała. Works of the Committee on the Geography of Industry of the Polish Geographical Society, 26, 160-172.

11. Halim H., Abdullah R., Nor M.J.M., Aziz H.A., Rahman N.A. 2017. Comparison between measured traffic noise in Klang Valley, Malaysia and existing prediction models. Engineering Heritage Journal, $1(2), 10-14$.
12. Hamad K., Ali K.M., Shanableh A. 2017. Modeling roadway traffic noise in a hot climate using artificial neural networks. Transportation Research Part D: Transport and Environment, 53, 161-177.

13. Huang B., Pan Z., Wang G. 2015. A methodology to control urban traffic noise under the constraint of environmental capacity: a case study of a double-decision optimization model. Transportation Research Part E, 41, 257-270.

14. Hume K., Brink M., Basner M. 2012. Effects of environmental noise on sleep. Noise and Health, 14, 297-302.

15. Jacyna M., Wasiak M., Lewczuk K., Karoń G. 2017. Noise and environmental pollution from transport: decisive problems in developing ecologically efficient transport systems. Journal of Vibroengineering, 19(7), 5639-5655.

16. Jarosińska D., Héroux M-E., Wilkhu P., Creswick J., Verbeek J., Wothge J., Paunović E. 2018. Development of the WHO Environmental Noise Guidelines for the European Region: An Introduction. International Journal of Hygiene and Environmental Health, 15(4), 813.

17. Jeon J.Y., Hong J.Y., Kim S.M., Kim K-H. 2018. Noise Indicators for Size Distributions of Airborne Particles and Traffic Activities in Urban Areas. Sustainability, 10, 4599.

18. Kaddoura I., Kröger L., Nagel K. 2017. An activitybased and dynamic approach to calculate road traffic noise damages. Transportation Research Part D: Transport and Environment, 54, 335-347.

19. Ko J.H., Chang S.I., Kim M., Holt J.B., Seong J.C. 2011. Transportation noise and exposed population of an urban area in the Republic of Korea. Environment International, 37, 328-334.

20. Kreuzberger N., Chaix B., Brondeel R., Méline J., Aarbaoui T.E. 2019. Transport-related noise exposure in a representative sample of Île-de-France residents: A data-enrichment approach. Journal of Transportation and Health, 12, 220-228.

21. Lam K., Chung Y. T. 2012. Exposure of urban populations to road traffic noise in Hong Kong. Transportation Research Part D: Transport and Environment, 17(6), 466-472.

22. Lam W.H.K., Tam M.L. 1998. Reliability analysis of traffic noise estimates in Hong Kong. Transportation Research Part D, 3(4), 239-248.

23. Lee E.Y., Gu J., Park H., Yun H., Kim S., Lee W., Han J., Ch J-S. 2014. Estimation of Populations Exposed to Road Traffic Noise in Districts of Seoul Metropolitan Area of Korea. International Journal of Hygiene and Environmental Health, 11(3), 2729-2740.

24. Lee E.Y., Jerrett M., Ross Z., Coogan P.F., Seto E.Y.W. 2014. Assessment of traffic-related noise in three cities in the United States. Environmental Research, 132, 182-189.

25. Li Q., Qiao F., Yu L. 2016. Risk Assessment of 
In-Vehicle Noise Pollution from Highways. Environment Pollution and Climate Change, 1, 107.

26. Manvell D., Hartog van Banda E. 2011. Good practice in the use of noise mapping software. Applied Acoustics, 72, 527-533.

27. Mehdi, M.R.; Kim, M.; Seong, J.C.; Arsalan, M.H. Spatio-temporal patterns of road traffic noise pollution in Karachi, Pakistan. Environ. Int 2011, 37, 97-104.

28. Monrad M., Sajadieh A., Christensen J.S., Ketzel M., Raaschou-Nielsen O., Tjønneland A., Loft O.S., Sørensen M. 2016. Residential exposure to traffic noise and risk of incident atrial fibrillation: a cohort study. Environment International, 92-93, 457-463.

29. Nassiri P., Karimi E., Monazzam M.R., Abbaspour M., Taghavi L. 2016. Analytical comparison of traffic noise indices - a case study in District 14 of Tehran City. Journal of Low Frequency Noise, Vibration and Active Control, 35(3), 221-229.

30. Night noise guidelines for Europe - WHO/Europe - World (2009). Available online: https://www. euro.who.int/en/health-topics/environment-andhealth/noise/publications/2009/night-noise-guidelines-for-europe (accessed on 20 December 2019).

31. Ongel A., Sezgin F. 2016. Assessing the effects of noise abatement measures on health risks: a case study in Istanbul. Environmental Impact Assessment Review, 56, 180-187.

32. Park T., Kim M., Jang C., Choung T., Sim K-A., Seo D., Chang S.I. 2018. The Public Health Impact of Road-Traffic Noise in a Highly-Populated City, Republic of Korea: Annoyance and Sleep Disturbance. Sustainability, 10(8), 2947.

33. Paull N., Krix, D., Torpy F., Igra P. 2020. Can Green Walls Reduce Outdoor Ambient Particulate Matter, Noise Pollution and Temperature? International Journal of Hygiene and Environmental Health, 17(14), 5084.

34. Phan Thi H.Y., Yano T., Sato T., Nishimura T. 2010. Characteristics of road traffic noise in Hanoi and Ho Chi Minh City, Vietnam. Applied Acoustics, 71, 479-485.

35. Regulation of the Minister of the Environment No. 140 item 824, 16 June 2011 on the requirements for measuring substances or energy levels in the environment by the manager of a road, railway line, tramway line, airport or port.

36. Ross Z., Kheirbek I., Clougherty J.E., Ito K., Matte T., Markowitz S., Eisl H. 2011. Noise, air pollutants and traffic: Continuous measurement and correlation at a high-traffic location in New York City. Environmental Research, 111(8), 1054-1063.

37. Roswall N., Raaschou-Nielsen O., Jensen S.S., Nneland A.T., Rensen M.S. 2018. Long-term exposure to residential railway and road traffic noise and risk for diabetes in a Danish cohort. Environmental Research, 160, 292-297.

38. Sánchez-Sánchez R., Fortes-Garrido J.C., Bolívar
J.P. 2015. Characterization and evaluation of noise pollution in a tourist coastal town with an adjacent nature reserve. Applied Acoustics, 95, 70-76.

39. Sehult T.J. (1972). Community noise rating. Applied Science Publishers, London and New York, pp. 10-25

40. Seidler A., Wagner M., Schubert M., Dröge P., Römer K., Pons-Kühnemann J., Swart E., Zeeb H., Hegewald J. 2016. Aircraft, road and railway traffic noise as risk factors for heart failure and hypertensive heart disease-a case-control study based on secondary data. International Journal of Hygiene and Environmental Health, 219 (8), 749-758.

41. Silva L.T., Mendes J.F.G. 2012. City Noise-Air: An environmental quality index for cities. Sustainable Cities and Society, 4, 1-11.

42. Suárez E., Barros J. 2014. Traffic noise mapping of the city of Santiago de Chile. Science of the Total Environment, 466-467, 539-546.

43. Swain B.K., Panda S.K. Goswami S. 2012. Dynamics of road traffic noise in Bhadrak city, India. Journal of Environmental Biology, 33, 1087-1092.

44. Tang A.M., Hughes P.N., Dijkstra T.A., Askarinejad A., Brenčič M., Cui Y.J., Diez J.J., Firgi T., Gajewska B., Gentile F., Grossi G., Jommi C., Kehagia F., Koda E., Ter Maat H.W., Lenart S., Lourenco S., Oliveira M., Osinski P., Springman S.M., Stirling R., Toll D.G., Van Beek V. 2018. Atmosphere-vegetation-soil interactions in a climate change context; impact of changing conditions impacting on engineered transport infrastructure slopes in Europe. Quarterly Journal of Engineering Geology and Hydrogeology, 51(2), 156-168.

45. To W., Mak C., Chung W. 2015. Are the noise levels acceptable in a built environment like Hong Kong? Noise and Health, 17(79), 429-439.

46. Traseo. Available online: https://www.traseo. $\mathrm{pl} /$ trasy/kategoria/samochod/query/BielskoBia\%C5\%82a (accessed on 20 December 2019).

47. Wen X., Lu G., Lv K., Jin M., Shi X., Lu F. 2019. Zhao, D. Impacts of traffic noise on roadside secondary schools in a prototype large Chinese city. Applied Acoustics, 151, 153-163.

48. Wen X., Lu G., Lv K., Jin M., Shi X., Lu F., Zhao D. 2019. Impacts of traffic noise on roadside secondary schools in a prototype large Chinese city. Applied Acoustics, 151, 153-163.

49. World Health Organization. Available online: https://www.euro.who.int/en/publications/abstracts/environmental-noise-guidelines-for-theeuropean-region-2018 (accessed on 20 December 2019).

50. World Health Organization-WHO, Regional Office for Europe Environmental noise (2018), p. 326

51.Zielone wrota. Available online: http://www. zielonewrota.pl/art_v.php?art=2765\&p (accessed on 20 December 2019). 